\title{
Hastaların İnternet Kullanımı ve Elektronik Ortamdaki Sağlık Bilgilerine Erişim Davranışları
}

\author{
The Internet Usage Behaviour and Access Patterns of the Patients to the Health \\ Information on the Internet
}

\author{
Haluk ZÜLFÍKAR*
}

İletişim/Correspondence: Haluk ZÜLFIKKAR Adres/Adress: İstanbul Üniversitesi İktisat Fakültesi Beyazıt Kampüs 34452 İstanbul Tel: 0212440 0000/11707 E-mail: zulfikar@istanbul.edu.tr

\begin{abstract}
$\ddot{O} Z$
İnternet dünyasındaki hızlı değişim să̆lık sektöründe de kendini göstermiş ve hastalıkların teşhis ve tedavisinin yanında, hasta algılarl, tutum ve davranışlarında da değişmelere sebep olmuştur. Daha önce pasif bilgi alıcisı konumunda olan hastalar, yapısal değişimle aktif bilgi tüketicilerine dönüşerek, hasta ve sağlık personeli arasındaki ilişkilerinde farklılaşmaların ortaya çıkmasını să̆lamıştır.

Daha aktif ve etkin bu yeni hasta modeli, tedavi sürecinde uzmanla kolkola hareket eden bir hasta tavrının ortaya çıkmasını mümkün kılmıştır. Zaman yetersizliğinden kendisine verilemeyen eksik bilgileri internet üzerinden tamamlayabilen, doktor tarafindan söylenemeyen kötü bilgilere erişebilen bu hasta profili, aynı zamanda hekimin mesleki yetkinlik ve yeterliliklerini de sorgulayan bir özellik göstermektedir. Nitekim hekimlerin \%13,6 sı her gün, \%36,4'sı ise haftada en az bir hastasının internetten elde ettiği bilgiyi kendisiyle tartışmak istediğini belirtmektedir.

Ayrıca anahtar kelimeler kullanarak ve ağıllıll olarak arama motorları üzerinden sağlık bilgisi aramakta olan bu hastaların, doğruluğu sorgulanabilen, çok ve karışık bilgi kümesiyle karşı karşıya kaldığı da tespit edilmektedir. Öte yandan, hastaların internet ve sosyal ăglarl, daha genel bir ifadeyle elektronik/online iletişim alanlarını kullanarak doğru bilgiye erişimi ve bu bilgiyi doğru kullanımı ile săgllkl sosyalleşebilmesi ve barışık bir yaşam sürmesi de mümkün olabilmektedir. Bu derlemenin amacı, bireylerin hastalıklarını ve onun dolaylı etkilerini yönetebilmeleri için sağlıkla ilgili online tutum ve davranışlarını tanımlamaktır. Ayrıca çalışmada, kalıtsal ve nadir görülen hastalıklardan hemofili ve kanama bozukluğu hastalıklarına sahip bireylerin internet kullanımı ile ilgili tutum ve davranışları ile ilgili bilgiler de sunulmuştur. Anahtar Kelimeler: Sağlık araştırmaları, hastaların online tutumları, online sağlık bilgisi analizleri.
\end{abstract}

\section{ABSTRACT}

The fast change in the world of internet is also revealed in health sector which led to changes in both the diagnosis and treatment of illnesses together with some particular changes in patients' perceptions, attitude and behaviour. The patients who once used to be just passive information receivers have turned into active information users based on this structural change and this, in turn, led to differentiations in patient-medical doctor relationships.

This new type of patient, who is more active and efficient, is also in close contact with their doctor during the treatment process. This new patient profile also has a new set of behaviour as to seek the missing parts of the information which has not been adequately provided by the doctors due to time constraints and/or access the negative aspects of the information not provided by the doctors in addition to questioning the professional competence and expertise of their doctors. As a matter of fact the 13,6\% of the doctors state that every day at least one patient demands to discuss a piece of information they have gathered from the internet with themselves whereas 36,4\% of the doctors state that every week at least one patient demands to discuss a piece of information they have access over the internet with themselves.

Additionally, it was also found out that these patients who are searching for health related information by means of some key words, are, from time to time, faced with some complex clusters of information whose accuracy needs to be questioned. In this respect, it is highly probable that the internet and the social networks can prove to be useful for the patients to access the accurate information, to socialize properly and to lead peaceful lives.

The purpose of this study is to examine the online behaviour and attitudes of the patients which are indispensable in the way that these individuals can manage their illnesses and their related impacts. Additionally, in the present study, patients with hereditary and rarely encountered diseases such as haemophilia and bleeding disorders have been observed on the basis of their behaviour and attitudes together with their detailed and confidential information.

Key Words: Health research, online attitudes of patients, online health information analyses.

*Yard. Doç. Dr. İstanbul Üniversitesi İktisat Fakültesi

Yazının gönderilme tarihi: 05.08.2013

Yazının basım için kabul tarihi: 13.01.2014 


\section{GíRiş}

Günümüzde bilgi teknolojileri alanındaki baş döndürücü gelişim, içerdiği iletişim devrimi ile daha önce ulaşılması zor hatta imkansız olan bilgilere hızlı ve eşit imkanlarla ulaşım olanağı sağlamıştır (Bass ve ark. 2006). Dünya genelinde internet üzerinde konularına göre günlük aramalar ele alındığında, bunlar arasında sağlıkla ilgili başlıkların \% 4,5 oranında araştırıldığg tespit edilmiştir (Bass ve ark. 2006).

Yeni medya düzeni çerçevesinde elektronik yaşam ve internet üzerinden bilgiye erişebilme seçeneği, tüm insanların ve özellikle hastaların sağlıklarını yönetmede kendilerini daha etkin kılabilme imkanı sağlamaktadır. Böylelikle bireyler daha fazla bilgiyle karar verebilme ve sağlıkla ilgili davranışlarını yönetebilmegeliştirebilme imkanından faydalanabilmektedirler (Bass ve ark. 2006). Dolayisiyla hastaların internet üzerinden bilgi toplama girişimlerinin devamlılık arz eder bir yapıda olduğu düşünülmektedir. Modern tedavi yöntemleri ve yönetimindeki gelişme ve kalite artışı, evde tedavi imkanlarında önemli ölçüde artış ve değişimi beraberinde getirmiștir. Aynı şekilde mekan, zaman ve kişi ihtiyaçları boyutlarında sınırları değiştiren internet, kullanıcılarına bulunduğu yerden hareket etmeden diğerleri ile buluşabilme, beraber olabilme imkanını sağlamıştır.

Bireyler çoğunlukla başta; kanser, kalp hastalıkları, hemofili ve kanama bozukluğu hastalıkları olmak üzere kronik hastalıklarla ilgili bilgileri internet ortamından araştırmaktadırlar. Hemofili ve kanama bozukluğu hastalıkları olan bireyler; kalıtsal bir hastalık olarak nesilden nesile sürmesi, aile içi etkileşime açık oluşu, sosyal izolasyon durumu yaşamaları, kanama sorunundan ötürü sorunlarıyla ilgili bilgiye acil ulaşım gereksinimi gibi nedenlerden dolayı en sık internetten bilgi arayan hasta grubu olarak tanımlanmıştır. Ayrıca bu hastalıklarla ilgili olarak, acil müdahale gereksinimi olan durumlarda, hizlı ve doğru bilgilenme ve etkin tedavi arasında kuvvetli ve pozitif yönlü bir ilişki olduğu belirtilmiştir. Bu durumda eğer bu hastalar internet aracılığı ile doğru bilgiye ulaşılırlarsa hastalık- larının yönetiminde başarılı olabileceklerdir (Barlow ve ark. 2007).

Hastaların sağlıkları ile ilgili konularda internet üzerinden yaptıkları araştırmalardaki motivasyonları ele alındığında, bunların iki boyutta toplanabildiği tespit edilmiştir (McMullan 2006).

Buna göre:

\section{Bireyin/hastanin hastaneye ya da doktora gitme-} den önce kendi kendine bağımsız araştırma süreci: $\mathrm{Bu}$ süreçte hasta internet üzerinde hastalığına ilişkin bilgi araştırarak doktora gitme ihtiyacının olup olmadığını tespit etmektedir.

\section{Hastane ya da doktor ziyareti sonrası internet üze-} rinde yapılan bilgi araştırma süreci: $\mathrm{Bu}$ süreçte ise, ihtiyaç duyulan ek bilginin temin edilmesi ya da sağl1k uzmanının kendisi ile paylaştığı bilgiden tatmin olmama, yetinememe veya değerlendirme ihtiyacı duyma durumunda ortaya çıkan bilgi edinme sürecidir.

$\mathrm{Bu}$ iki değişimin ortak bir sonucu olarak hastaların, özellikle kanama bozukluğu gibi kalıtsal hastalık sahibi bireylerin internet üzerindeki tutum ve davranışları, hastalıklarının gelişimi ve yönetiminde önemli farklılaşma ve gelişmelere neden olmuştur. Bilgisayar ve internet bağlantı gereksinimi, bu kanalla bilgi edinme üzerinde temel şart olarak tanımlanmaktadır (Mc Mullan 2006).

$\mathrm{Bu}$ derlemenin amac1, bireylerin hastalıklarını ve onun dolaylı etkilerini yönetebilmeleri için sağlıkla ilgili online tutum ve davranışlarını irdelenmektedir. Ayrıca çalışmada, kanama bozuklukları ve hemofili gibi kalıtsal ve nadir görülen hastalıkları olan bireylerin hastalıkları ile ilgili internetten bilgi edinme tutum ve davranışlarına odaklanılarak konu açıklanmaya çalışılmiştır.

\section{YÖNTEM}

Derlemenin birinci amacı ile ilgili olarak; genel kapsamdaki hastaların sağlık amaçlı internet kullanımı ve bu sürecin hasta kimlikleri ve hastalıkları üzerin- 
deki olası etkilerini ele alan, ağırlıklı olarak 2005 ve sonrası farklı ülkelerde gerçekleştirilen akademik çalışmalar incelenmiştir. Ancak internet kullanımlarının zaman içindeki değişim ve etkinliğini analiz edebilmek amacıyla, karşılaştırmaların birçoğunda 2000 y1lına kadar geri gidilmiştir. Çalışmanın ikinci amacı ile ilgili olarak ise; kanama bozukluğu ve hemofili hastalığı olan hastaların internet kullanımları, internet üzerinden bilgi edinme sistematikleri incelenmiştir.

Derleme sistematiğinde, temel olarak hastaların sağlık ile ilişkili bilgi alabilecekleri kaynaklar ve internetten yararlanma tarzlarına, özel kapsamda ise arama motorları, web siteleri, sosyal ağlar, forumlar-bloglar ve e-mail grupları gibi farklı bilgilerin yanı sıra, sosyalleşme ve iletişim alanlarına odaklanılmaya çalışılmıştır. Yanı sıra elektronik ortamdaki bilgi erişim alanları ve buradan ulaşılan bilginin kullanımı, bunların hasta ve doktor/sağlık personeli ilişkisinde oluşturduğu değişimler ile hastalıkla baş etme üzerindeki etkilerine ilişkin çalışmalar incelenmiştir.

\section{Sağlık Amaçı Bilgi Edinmeye İlişkin Dünya ve Türkiye'de İnternet Kullanımı}

Amerika Birleşik Devletlerinde (ABD) 2008 sonunda tamamlanan ve 18 üstü yaş grubu 2253 kişi üzerinde gerçekleştirilen araştırma sonucuna göre, erişkin nüfusun \%74'ü internet kullanırken, ortalama \%61'inin internet üzerinden sağlık ve medikal konularda araştırma yaptığ 1 tespit edilmiştir. 2013 yılı itibarıyla yetişkin nüfus içinde internet kullanıcısı oranının \%85 değerine ulaştığı belirlenmiştir. Söz konusu kullacıların internet kullanım amaçlarıarasında sağlık bilgisi arama oranının \%72 olduğu tespit edilmiştir (IWS 2013; PIALP 2009). Nitekim zaman içinde değişen bu oran, internet kullanıcılarının araştıracakları konuları belirlemede giderek bilinçlenmeye başladığı şeklinde yorumlanabilir.

İngiltere'de, internetten sağlık bilgisi edinen 3209 birey ile yapılan biraraştırmada, sağlık ile ilgili bilgi aramak için internet kullanım sıklığı ile sosyo-ekonomik düzey arasında istatistik açıdan anlamlı ilişkiler belir- lenmiştir. Buna göre, üst sosyo-ekonomik gruba ait bireylerin alt sosyo-ekonomik gruba ait bireylere göre daha fazla sağlık bilgisi aramakta olduğu belirlenmiştir (Murray ve ark. 2003).

İnternetten elde edilen sağlık bilgisine ilişkin alt analizlerde, internet üzerinden sağlık bilgisi edinenlerin \%56'sının, bu kanalla sağlık bilgisi edinmenin kendi ya da bir diğer kişinin sağlığını kontrol etme ve yönetebilme üzerinde bilinç sağladığını, \% 49'unun ise, internet üzerinden elde edilen sağlı bilgisinin kendilerinin diyet yapabilme, stres yönetimi, egzersiz yapma gibi konularda düşünme tarzlarını değiştirdiğini ifade ettikleri belirlenmiştir (PIALP 2009). Amerika Birleşik Devletleri'nde yapılan kanser araştırmaları sonuçlarına göre, kanser hastalarının \%92'si, internet üzerinden elde edilen sağlık bilgilerinin karar süreçleri üzerinde kendilerini güçlendirdiğini ve doktorla konuşmada kendilerine anlamlı derecede yardımcı olduğunu belirtmişlerdir (Eysenbach 2003).

Başka bir çalışmada ise, internetten elde edilen bilginin sağlık danışmanlarıyla tartışılması durumunda, sağlıkla ilgili karar süreçlerinde çok daha etkin kullanabildiği saptanmıştır (Broom 2005).

İnternet üzerinden bilgiye erişim, özel ya da herhangi bir mekana gereksinim duyulmaması, zaman sın1r1 olmaksızın 24 saat erişim imkanı, evden ve hastanın kendini tanıtmadan siteme erişebilmesi, kendi hastalığına sahip diğer ve hatta akran hastalara ulaşabilme imkanının yüksekliği gibi üstünlüklere sahip olabilir (Nicholas ve ark. 2003). Nitekim, Wanless (2002), tarafından yapılan bir çalışmada; hastaların \%63’ü, internetten elde ettikleri bilginin gereksiz şekilde doktor ziyaretinde bulunmalarının önüne geçtiğini belirtmişlerdir. Ancak, bu durum kanser vb. ağır ve kronik hastalığı olan bireylerin bazıları üzerinde olumsuz sonuçlar doğurabilmektedir. Özellikle tedavi görmekte olan kanser hastalarının, internet üzerinden elde ettikleri doğruluk kontrolleri yapılmamış bilgileri kullanmalarının; tedaviyi yarıda bırakmalarına, farklı tedavi seçenekleri uygulamalarına ve hayati zararlar görmelerine neden olduğu saptanmıştır (Kiley 2002). Diğer 
bir çalışmada ise, kanser hastaları internet üzerinden elde ettikleri bilgiyi; $\% 31$ oranıda etkileyici, $\% 27$ oranında kafa karıştırıcı, \% 76 oranında ise çelişkili bulmuşlardır (Eysenbach 2003).

Amerika Birleşik Devletleri'nde, aile hekimliği hizmeti alan 18 ve üzeri yaş grubundaki 1289 hasta birey üzerinde yapılan araştırmada, katılımcıların \%98,7'sinin internetten elde ettikleri sağlık bilgilerini anlaşılır, \% 98,1'inin isegüvenilir bulduğu tespit edilmiștir. Ayrıca bu çalışmada, bilginin güvenirlik düzeyi ölçütleri olarak; devlet ya da profesyonel kurumlar tarafindan onanmış olmasının (\%48), güvenilir yazar ya da kaynaklar tarafindan yazılmış ve destekleniyor olmasının (\%47) ve bilginin anlaşılabilirliğinin (\%45) etkin unsurlar olduğu saptanmıştır. Aynı araştırmada, elde edilen sağlık bilgisinin kontrol edilmesinde ilk s1rada \%54 ile doktora sorma ya da doktor ile irdelemenin geldiği, ikinci sırada \%48 ile farklı sitelerdeki bilgilerle karşılaştırmanın ve üçüncü sırada ise \% 40 ile kitap, dergi, TV ve benzeri internet dışı geleneksel bilgi kaynaklarından kontrol etmenin yer aldığ 1 belirlenmiştir (Schwartz ve ark. 2005).

Sağlıkla ilgili karar sürecinde önemli oranda kullanım bulan internet kaynaklı sağlık bilgileri, \%74 oranında "doğrudan kullanıcı" olarak kişinin kendisi veya "dolaylı kullanıcı" olarak aile bireyleri için elde edilmeye çalışılmaktadır (Schwartz ve ark. 2005). Amerika Birleşik Devletleri'nde, kanser hastaları üzerine yapılan başka bir çalışmada, hastaların \%87.2 oranında aile veya tanıdıkları vasıtasıyla internete yönlendirildiği belirlenmiştir. Bu sonuca göre, aile veya tanıdıkların öneri veya yönlendirmelerinin, hastalar tarafından olağan bir durum olarak algılandığı gözlenmiştir. Ayrıca kanser gibi ciddi hastalıklarda bilgi edinme sistematiğinde farkl1laşmaların oluştuğu, tespit edilen bir diğer bulgudur. Nitekim \%8,6 oranındaki bir kanser hastas1 grubunun, hastalıklarını öğrendikten sonra interneti, etkin ve doğru kullanabilmek amacıyla eğitim almaya başladıklarını belirtmeleri bu durumun bir sonucu olarak yorumlanabilir (Bass ve ark. 2006).
İnternet üzerinden bilgi arama aşamaları incelendiğinde, bireylerin büyük çoğunluğu'nun $(\% 82,5)$, arama motorları üzerinden anahtar kelime yazarak aramaya başladığ $1, \% 33,7$ 'sinin genel olarak sağlıkla ilgili olan sitelerden arama yaptığ $1, \% 12.5$ gibi düşük bir oranın ise özel sağlık sitelerine girerek bilgiye ulaştıkları tespit edilmiştir (Schwartz ve ark. 2005).

Türkiye'de ise son üç ay içinde kişisel amaçlarla internete giren bireyler arasında sağlıkla ilgili bilgi arayanların oran 2011 yılında \%54,1 iken 2013 y1lında artarak \%59,6 değerine yükselmiştir. Daha genel bir ifadeyle, 2013 y1lında internete giren her 10 kişiden yaklaşık 6'sının sağlıkla ilgili bilgi almak için interneti kullandığı tahmin edilmiştir. 2013 yılı itibarıyla internet kullanıcılarının internete girme durumları Tablo 1 'de gösterilmiştir. Tablo 1'de görüldüğü gibi sağl1k ile ilgili bilgi arama amaciyla internete girme oran1, kır kesiminde $\% 46,2$, kent kesiminde ise $\% 62,4$ 'dir (TÜIK 2013). Bu oranlar internetin, dünyada olduğu gibi ülkemizde de sağlık konusunda bilgi paylaşımı, hasta bireylerin yanısıra sağlıklı bireylerin de bilgilendirilmesi ve eğitilmesi amacıyla kullanılabileceğini düşündürmektedir.

Sonuç olarak, internet üzerinde aranan bilginin türü, arama şekli, erişilen bilginin doğruluğunun ve güvenilirliğinin belirlenmesi oldukça zor ve önemli aşamalar olarak hastanın karşına çıkmaktadır. Bu zorluğun aş1lamaması durumunda, hastaların bilinçli tercihlere ve doğru kararlara varabilmelerinin, uzun dönemde sağlık durumlarını ile kendilerini doğru yönetebilmelerinin güç olacağı gözlenmektedir.

\section{Hasta Bireylerin İnternet Kullanım Davranışları: Kanama Bozukluğu ve Hemofili Hastalığı Olan Hastalar}

Kalıtsal bir hastalık olarak nesilden nesile sürmesi, aile içi etkileşime açık oluşu, sosyal izolasyon duru$\mathrm{mu}$, kanama sorunundan ötürü bireylerin, sorunlarıla ilgili bilgiye acil ulaşım gereksinimi gibi nedenlerden dolayı, kanama bozukluğu ve hemofili hastalığı olan bireylerin internet kullanım davranışları incelenmektedir (Barlow ve ark. 2007). 
Tablo 1. Türkiye'de 2013 Y1lı Kişisel İnternet Kullanma Amaçları (\%)

\begin{tabular}{|c|c|c|c|}
\hline Amaçlar & Türkiye & Kent & Kır \\
\hline Online haber, gazete ya da dergi okuma & 75.6 & 76.4 & 71.8 \\
\hline İnternet üzerindeki sosyal gruplara katılma & 73.2 & 72.1 & 78.3 \\
\hline E - Posta gönderme/alma & 62.5 & 63.8 & 56.1 \\
\hline Mal ve hizmetler hakkında bilgi arama & 59.9 & 62.7 & 46.3 \\
\hline Sağlıkla ilgili bilgi arama (yaralanma, hastalık, beslenme, vb.) & 59.6 & 62.4 & 46.2 \\
\hline İnternet üzerinden telefonla görüşme / video görüşmesi (webcam ile) & 55.1 & 56.6 & 47.4 \\
\hline Eğitim ve kurslarla ilgili bilgi arama & 45.9 & 47.7 & 37.5 \\
\hline Herhangi bir konu ile ilgili bilgi almak için Wikipedia, On-line ansiklopedi vb. kullanma & 32.6 & 33.8 & 26.2 \\
\hline $\begin{array}{l}\text { Web siteleri aracılığıyla toplumsal veya siyasal konular ile ilgili görüşleri okuma veya } \\
\text { paylaşma }\end{array}$ & 28.7 & 28.9 & 28 \\
\hline Seyahat veya seyahat ile ilgili konaklama için online hizmetleri kullanma & 26.6 & 27.4 & 25.5 \\
\hline İnternet bankacılığı & 24.8 & 26.8 & 15.4 \\
\hline Düzenli olarak bilgi almak için haber servis ya da ürünlerine abone olma & 21.3 & 21.8 & 18.7 \\
\hline Yazılım indirme (oyun yazılımları hariç) & 19.1 & 20 & 14.7 \\
\hline İş arama ya da iş başvurusu yapma & 12.9 & 13.8 & 8.4 \\
\hline Toplumsal veya siyasal bir konuda online bir oylamaya katılma & 12.8 & 13.6 & 9.1 \\
\hline Mal veya hizmet satışı & 9.3 & 10 & 6 \\
\hline Herhangi bir konuda online (çevrimiçi) eğitim alma (yabancı dil, bilgisayar vb.) & 8.4 & 9 & 5.5 \\
\hline Profesyonel bir gruba katılma & 4.2 & 4.7 & 1.7 \\
\hline
\end{tabular}

İngiltere'de, 2011 yılında 11-18 yaş adolesan grubu 47 hemofili hastası üzerine yapılan bir çalışmada, hastalığını ve tedavisini detaylıca öğrenen hastaların, daha az fiziksel ve duygusal problem yaşadı̆̆ $\mathrm{n}$ 1 daha iyi yönetebildiği belirlenmiştir (Khair ve ark. 2011).

Hemofili ve benzeri kanama bozukluğu hastalıkları, "ender görülen hastalıklar" arasında yer almaktadır. Özellikle ağır hemofili (hemofili A) hastası olan erişkinler ve çocuklar, hareket kısıtlaması, yaşıtları ile az vakit geçirme, ailenin koruyucu kısıtlamaları gibi nedenlerle, akranlarıyla yeterli düzeyde ve kalitede beraber olamamaktadırlar. Böylelikle çocuk ve adolesan hastalarda ortaya çıkan akran desteği eksikliği, söz konusu çocukların tüm boyutlarıyla izole yetişmelerinde önemli bir unsur olarak ortaya çıkabilmektedir. Günümüz internet dünyasındaki sosyal ağlar, forumlargruplar, bloglar, email listeleri gibi sosyal ve bilgi paylaşımı siteleri ve ağları, hastalara bilgi ve tecrübelerini paylaşma ve sosyalleşme imkanını sağlamaktadır. Bu şekliyle internet, söz konusu hastalar ile benzer yapı ve şartlardaki hastaların, sağlık ihtiyaç ve hizmetlerini kolaylaştırıcı yeni ve güçlü bir araç olarak ortaya çıkmaktadır (Khair ve ark. 2012). Görülmektedir ki özellikle adolesan hemofili hastaları, internet üzerinde içerik bilgisi edinmenin ötesinde, ağırlıklı olarak sosyalleşmek amacıyla internetten yararlanmaktadır.

Dünya genelinde hastalığın tedavi ve kontrolündeki tüm gelişmelere karşın, 1990 yılına göre 2020 yılına kadar hemofili hasta sayısının yaklaşık \%25.7 artışla 440.000'e ulaşması beklenmektedir (Lee1998). Tahminler göstermektedir ki her ne kadar modern tedavi ile yaşam kalitesi ve yaşam süresi uzayıp, sakatlıklarda azalma yaşansa da, hemofili hastalarının yaşadığ sıkıntılar ve sorunların ele alınma gereksinimi devam edecektir. Nitekim son yıllarda dünya genelinde yaygınlaşarak kabul gören evde tedavi yaklaşımı, özellikle evde tedavi hizmetlerinin artış ve maliyetlerinde- 
ki mukayeseli düşüklük gibi olumlu özelliklerinin yanında, hemofili hastalarının bir araya gelme, yüz-yüze sosyalleşme olanaklarında azalmaya neden olabilmektedir. Nitekim kanama bozukluğu ve hemofili hastalarının bu gelişmelerin etkisiyle, daha fazla sosyal izolasyon içinde yaşamlarını sürdürmek zorunda kalabildiği gözlenebilmektedir.

İngiltere'de, 307 kanama bozukluğu ve hemofilili birey üzerinde yapılan çalışmada, erişkin hastaların $\% 48$ 'inin sosyal, duygusal ve eğitim ile ilgili bilgilere ihtiyaç duydukları belirlenmiştir. Aynı şekilde kanama bozukluğu hastaları arasında kadın hastaların (\%46) erkek hastalara (\%20) göre, anlamlı bir üstünlükle bu bilgileri aile ya da arkadaşlarından almayı tercih ettikleri saptanmıştır (Barlow ve ark. 2007). Yetişkin hemofilili bireyler ve kanama bozukluğu olan diğer hastaların \%90'1 toplumun bu hastalığ1 ve kendilerini yeterince tanımadığını belirtmekte ve yaşamlarındaki her iki kişiden birinin (\%52) kendisinde kanama bozukluğunun olduğunu bilmediğini ifade etmektedirler (Barlow ve ark. 2007). Sonuç olarak, hemofili ve diğer kanama bozukluğu hastalıkları konusunda yaşadıkları toplumda bilgi ve anlayış eksikliğinin olduğu kanısına sahip bu hastalar, ruhsal ve fiziksel olarak toplumdan uzaklaşarak izole yaşamaya başlamakta ve hastalıkları ile ilgili bilgilere de internet üzerinden erişmeye tercih etmektedirler.

Erişkin hemofili hastalarının \%76'sı, sağlık uzmanından yüz-yüze bilgi almayı tercih ettiklerini, doktorların kendilerini ve ihtiyaçlarını tamamıyla anladığını belirtmişlerdir. Söz konusu bireyler her ne kadar hemofili ile ilgili web sitelerinin net bilgi içerdiğini belirtseler de, bilgi edinmede ağırlıklı olarak kitap, dergi, gazete, broşür gibi klasik kaynakları tercih etmektedirler (Barlow ve ark. 2007). Erişkin hemofili hastalarında aileden psikolojik destek aldığını belirtenlerin oran1 \%90 dir (Barlow ve ark. 2007). Başka bir ifadeyle gerek erişkin gerek ergen hemofiliklerin internet üzerinden bilgi edinmeyi diğer hastalara göre daha az tercih ettikleri $(\% 25,4)$, buna karşın sosyal ağ kullanım oranlarının çok yüksek olduğu (\%81) tespit edilmektedir. Yukarıda ifade edildiği gibi, psikolojik açı- dan güçlü olmayan, kaygı, depresyon sorunu olup alkol ve uyuşturucu eğilimi olan erişkinlerin, yanısıra ergen hastaların, interneti sosyalleşme, paylaşma ve rahatlama aracı olarak tercih etmeleri söz konusu olmaktadır. Nitekim ergenlerde online sohbetin \%76,5 gibi yüksek bir oranında gerçekleşmesi bunun bir sonucu olarak yorumlanabilir.

Erişkin hastaların en çok yeni araştırma projeleri (\%57) ve eklem hasarları (\%48) konusunda bilgi ihtiyacı duymalarına karşın, gençlerin kendi akranlarından ve cinsel sağl1k, hayat tarzları, uyuşturucu gibi hassas konularda öneriler aradığı belirlenmiştir (Barlow ve ark. 2007).

Adolesan hemofiliklerin, internette arkadaşlarıyla yüksek orandaki sohbet eğilimine karşın, söz konusu kişilerle hemofili konusunda sohbet etme oranı ancak $\%$ 4,2 olarak gerçekleşmektedir. Buradan da görüleceği üzere sosyalleşme ve bir arada olma ihtiyacı, bilgi aramadan çok, rahatlama ve hemofili dışındaki konulara ait öneriler etrafında toplanmaktadır. Aynı şekilde yeni insanlarla bağıntı kurma, aynı ilgi alanına sahip kişilerle buluşma veya yurt dışındaki kişilerle sohbet etme (sırasiyla $\% 8,5, \% 8,5, \% 6,3$ ) seçenekleri son derece düşük oranlarla tercih edilmektedir (Khair ve ark. 2011). Nitekim internet kullanımı ve sosyal paylaşım ağlarının ortaya çıkıp yaygınlaşması, yaşam kalitesinin yükseltilmesine, tedaviye uyumun sağlanması bağlamında hasta ve yakınlarını güçlendirme potansiyeline ve tedavi için gerekli olan homojen bilgi paylaşımının sağlanmasına yardımcı olabilecektir (Khair ve ark. 2011).

\section{SONUÇ VE ÖNERILER}

$\mathrm{Bu}$ çalışmada, hasta bireylerin genel ve sağlık amaç11 olmak üzere internet kullanım davranışlarına ilişkin yapılan bilimsel çalışmalar derlenmeye çalışılmıştır. Çalışmalardan elde edilen sonuçlarda, internet üzerinden sağlık bilgisi edinen bireylerin yarıdan fazlas1, bu bilginin kendi ya da etrafındaki insanların sağl1ğını yönetmede katkı sağlayıcı olduğunu, kanser hastaları gibi bazı hastaların internetten elde ettikleri bilgilerin karar süreçlerini güçlendirdiğini ve doktorlarla 
görüşmelerinde kendilerine yardımcı olduğunu belirtmişlerdir. Buna karşın, kanser hastası gibi hastalardan bazılarının, internetten elde ettikleri bilgiler sonucunda hastalıklarını yönetmede zorlandığ 1 tespit edilmiştir. Nitekim yapılan çalışmalarda internetten elde edilen bilgilerin güvenirlilik sorgulanmasında dikkat çekici eksiklikler tespit edilmiştir.

Ergen hemofili hastalarında sı rastlanan ve internetin bilgi edinme yerine ağırlıklı olarak sosyalleşme için kullanımı, internet kullanımının hastalık tipi, hasta yaşı ve hasta beklentileribazında farklılaşmalar gösterebildiğine dair önemli bir sonuçtur. Nitekim hemofili gibi kanama bozukluğu olan erişkin hastaların, sağlık uzmanından yüz-yüze bilgi almayı tercih ettiği, ergen hastaların okula gitmeyi istemedikleri, okul yerine ihtiyaç hissettikleri bilgiyi etraflarındaki akranları ve ailelerinden almayı tercih ettikleri, hatta bu ergenlerin çok büyük bir kısmının akranlar1 ile fiziksel görüşme yapmadan iletişim kurduğuna dair çalışma sonuçları, internet kullanımının önemini vurgulamaktadır.

Doğuştan gelen ve yaşam boyu devam eden bir hastalığı olan erişkin kanama bozukluğu hastalarında, kayg1 ve depresyonun yüksek olduğu ve bu durumun söz konusu bireyleri, interneti yüksek oranda ve s1k kullanmaya yönlendirdiği saptanmıştır. Buradan hareketle internet seçeneğinin hastalar arasında bilgi edinme amacından çok, sosyalleşme amaçlı kullanıldığı da dikkat çekici bir diğer sonuç olarak incelenen çalışmalardan elde edilmiştir.

\section{KAYNAKLAR}

Bass, S. B. ve ark. (2006). Relatioship of internet health information use with patient behavior and self-efficacy: Experiences of newly diagnosed cancer patients who contact the national cancer institute's cancer information service. Journal of Health Communication, 11(2): 219-236.
Barlow, J. H., Stapley, J., Ellard, D. R., Gilchrist, M. (2007). Information and self-management needs of people living with bleeding disorders: A survey. Hemophilia, 13: 264-270.

Broom, A.(2005). Virtually he@1thy: The impact of internet use on disease experience and the doctor-patient relationship. Qualitative Health Research, 15(3): 325-345.

Eysenbach, G. (2003). The impact of the internet on cancer outcomes. CA Cancer J Clin., 53(6): 356-371.

Internet World Stats (IWS) (2013). Internet Usage \& Population Statistics 2012, http://www.internetworldstats.com/stats.htm $(31.12 .2013)$

Khair, K., Holland, M., Carrington, S. (2012). Social networking for adolescents with severe haemphilia. Haemophilia,18(3): 290-296.

Kiley, R. (2002). Does the internet harm health? British Medical Journal, 26(324): 235-241.

Lee, C. A. (1998). World Federation of Haemophilia Developing World Programmes. Haemophilia, 4(2): 259-263.

Mullan Mc, M. (2006).Patients using the internet to obtain health information: How this affects the patients-health professional relationship. Patient Education \& Counseling, 63(1): 24-28.

Murray, E. ve ark. (2003). The impact of health information on the internet on health care and the physician-patient relationship: National US Survey. Journal of Medical Internet Research, 5(3): 1727-1734.

Nicholas, D., Huntington, P., Gunter, B., Russell, C., Withey, R. (2003). The British and their use of the web for health information and advice: A survey. Aslib Proc., 55(5/6): 261-276.

Pew Internet\&American Life Project (PIALP) (2009). Health Information on the Internet, U.S.

Schwartz, K. L. ve ark. (2006). Family medicine patients' use of the internet for health information: A metronet study. Journal of American Board of Family Medicine: JABFM, 19(1): 39-45.

Türkiye İstatsitik Kurumu (TÜİK) (2013). Hanehalkı Bilişim Teknolojileri Kullanım Araştırması, Ankara.

Wanless, D. (2002). Securing our future health: Taking a Long Term View-Final Report. HMGO The Public Unquiry Unit, London. 